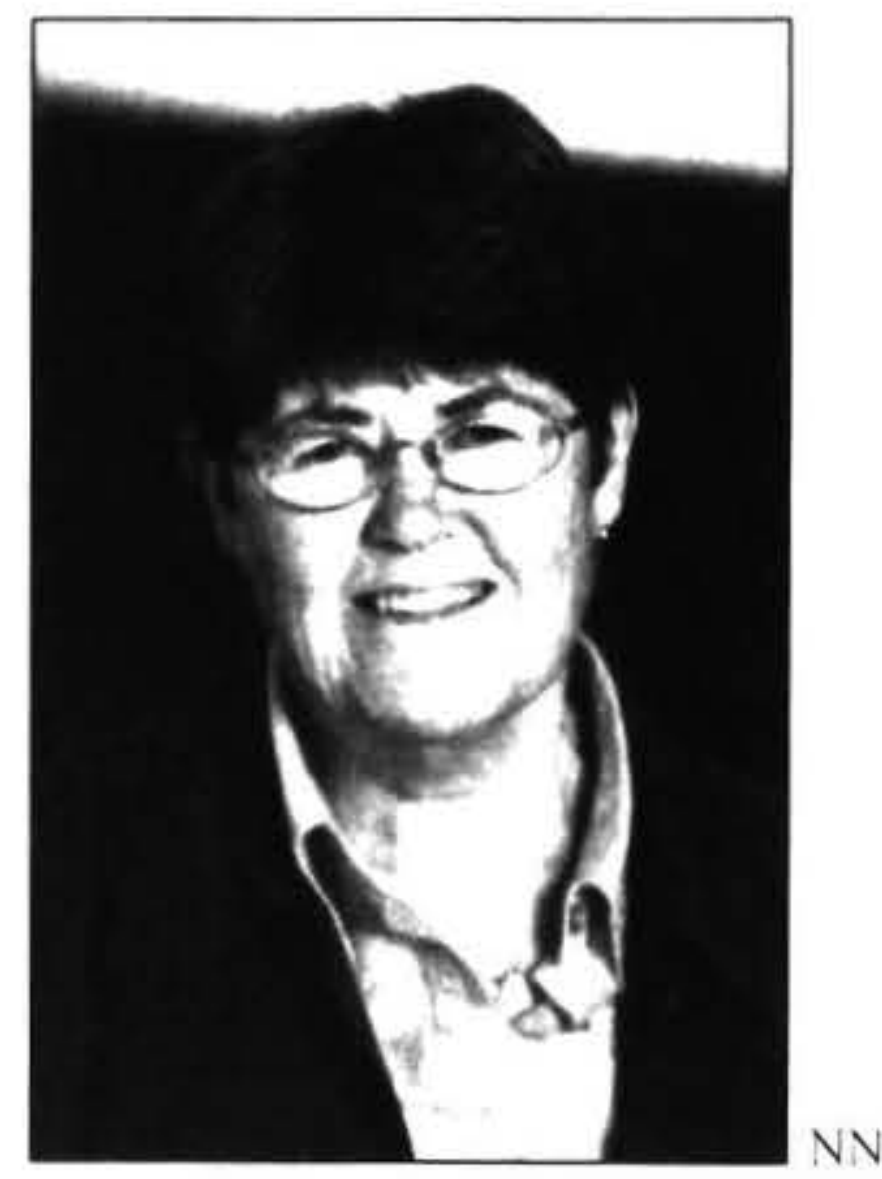

\title{
USE OF TEMPORARY NURSE MECHANISMS BY NEW \\ ZEALAND'S DISTRICT HEALTH BOARDS
}

\author{
Nicola North \\ School of Nursing, \\ The University of Auckland
}

\section{Frances Hughes}

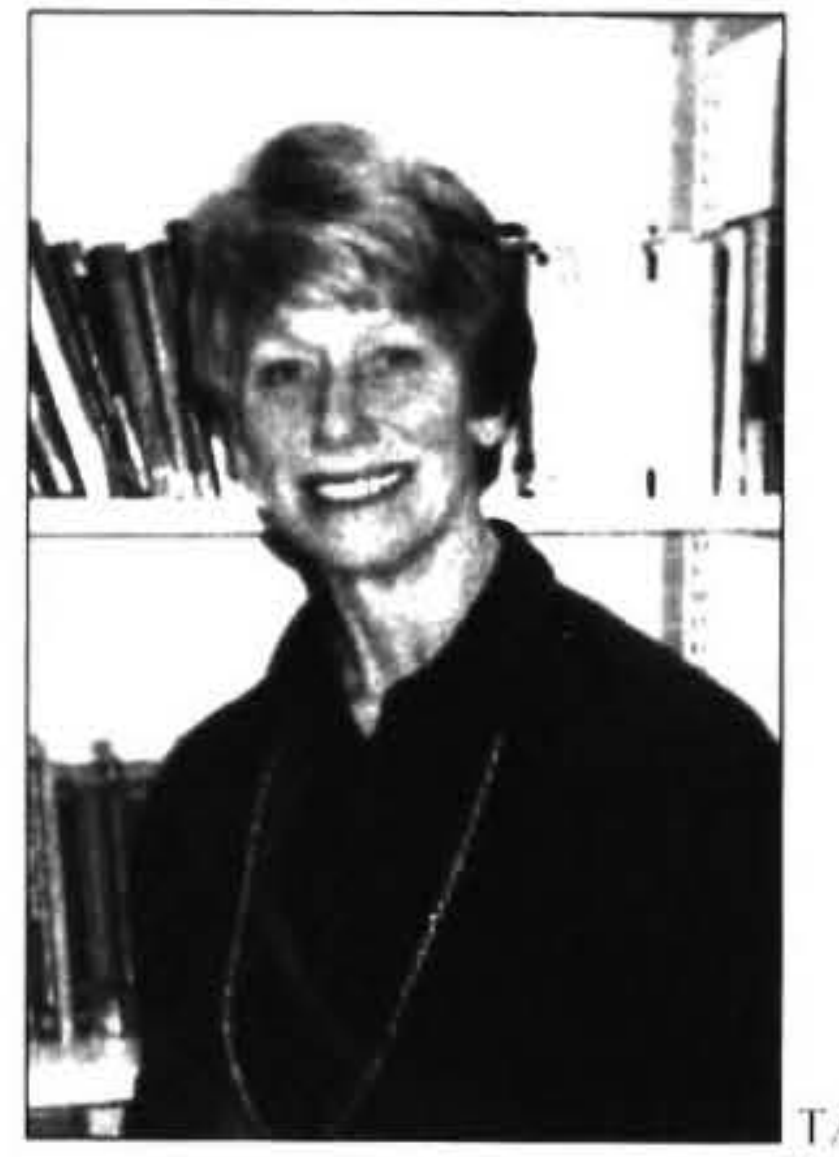

Faculty of Nursing. Midwifery and Health,

University of Technology Sidney

\section{Erling Rasmussen}

Department of Management and

Emploiment Relations,

The University of Auckland

\section{Mary Finlayson}

School of Nursing.

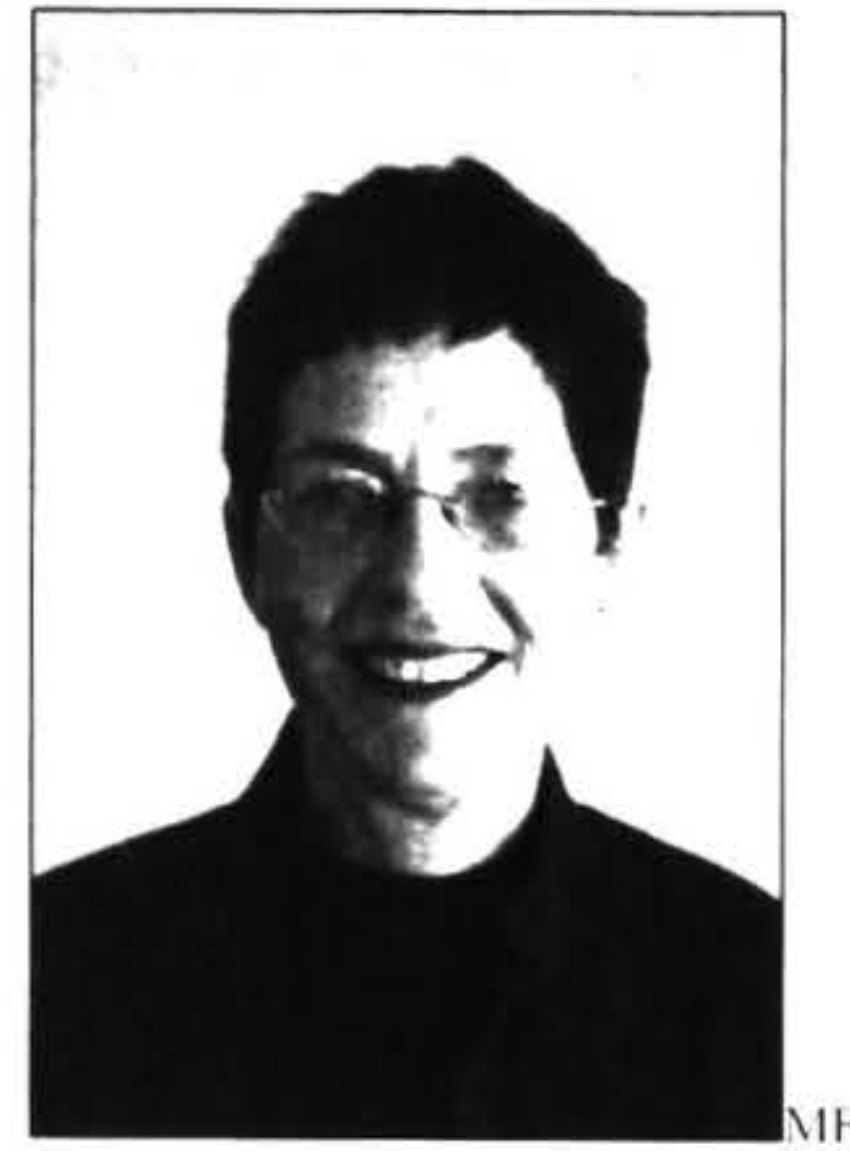

The University of Auckland

Toni Ashton

School of Population Health.

The University of Auckland

\section{Taima Campbell}

Nursing and Midwiferv. Auckland District Health Board
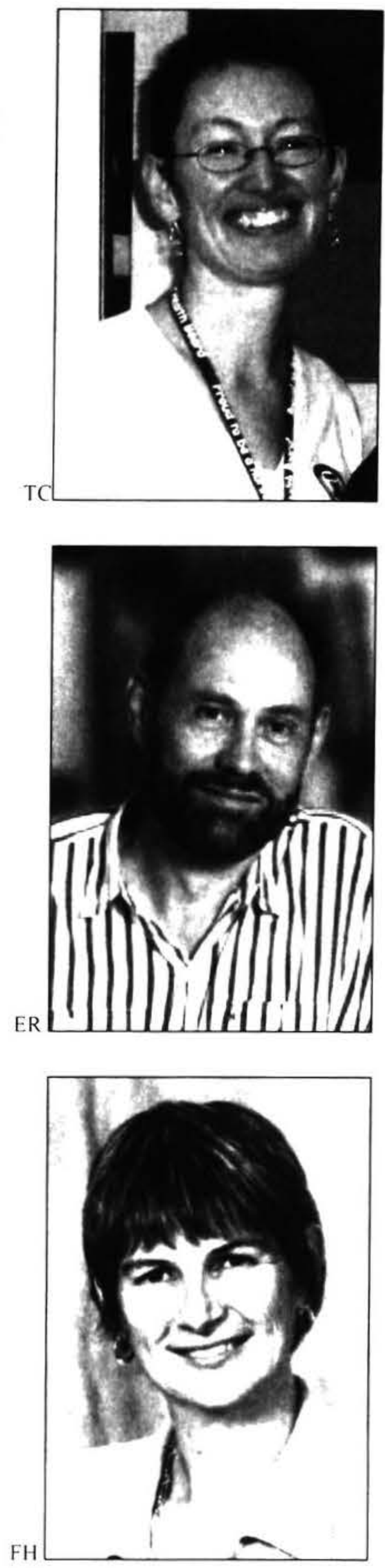

\section{Sharon Tomkins}

School of Nursing.

The University of Auckland

\section{Abstract}

Nursing shorlages is a concern glohalls: and in this context has emerged a research focus on reasons and costs of turnover and retention. A national study on the costs of nursing turnover in New Zealand public hospitals was

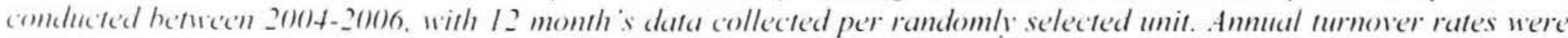

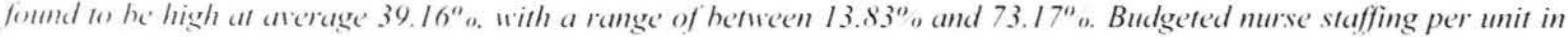
is expected to be sufficient to deliver mursing work for the patient population (occupancy: acuity and complexity) and provick for leare (ammual. sick. stuch: famils: herearement etc). In the contert of the studs it was assumed that 
temporary cover mechanisms were mainly to cover vacancies and occasional unplanned contingencies such as influenza affecting staff, and higher than normal demands for nursing work. The cost of temporary cover would therefore be a cost of turnover. An unexpected finding of the study was that temporary cover mechanisms were widely used, including when actual staff numbers were equal to or exceeded budget, and no consistent relationship with vacancies was evident. It was concluded that management of the nursing resource was driven by cost, not strategic. considerations. Published research on use of temporary cover and the effect of such practices on turnover of nurses provided a perspective to critique the finding.

\section{Introduction}

The single largest health professional workforce in hospitals both numerically and as a proportion (total, not per person) of the wage bill is its nursing services. The nature of nursing work and demand on nursing services complicates efficient budgeting and deployment, because nursing work is characterized by its non-deferrable nature and unpredictable volumes arising from fluctuations in acuity and demand. Budgeting for nursing full time equivalent numbers (FTEs) must take into account employment contracts provisions (e.g. annual, sick and bereavement leave, hours of work per shift and per week). In New Zealand public hospitals nursing working conditions are covered by the NZNO-DHB MECA agreement.

This paper reports on an aspect of data that was collected from a national sample of nursing units in New Zealand public hospitals participating in the Cost of Nursing Turnover study. Unexpected findings of the study were the widespread lower levels of actual permanent RN staff (reported as FTE) than budgeted, and the high use of temporary cover mechanisms. Use of temporary cover occurred not only to cover vacancies, as anticipated, but also occurred when RN FTE staffing was equal to or exceeded budgeted levels. The finding raised questions about the adequacy of $\mathrm{RN}$ staffing levels to deliver nursing services and led to a conclusion that management of the nursing resource is driven by considerations of cost, not strategic considerations.

Regarding the statutory context there are two considerations. District Health Boards in New Zealand have statutory obligations to provide the best health care and support services to New Zealanders in a fiscally prudent manner (Public Health \& Disability Act 2000). This implies that DHB owned facilities including hospitals should provide services that are competent, safe, and of high quality. As employers DHBs are also responsible for employee health and safety and for making sure the work done by employees is safe and healthy (Health and Safety in Employment Act 1992 \& 2002).

\section{Previous Research}

The use of temporary cover mechanisms in nursing to cover vacancies, shortages, leave, higher patient volumes and acuity is attracting researcher attention. An a priori consideration, however, concerns the adequacy of nurse staffing and nursing workforce management in the first place. A five-country study in the late 1990s that surveyed over 43,000 nurses showed high levels of job dissatisfaction (between $32.9-41 \%$ in 4 of the 5 countries), scores in the high burnout range for 29.1-
$43.2 \%$ in those 4 countries, and corresponding high rates of intent to leave, up to about $46 \%$. Only about a third of respondents in each country agreed that levels of RN staffing were sufficient to provide high quality care and to get the job done. Correspondingly high levels, up to $83.2 \%$, reported an increase in patient load (Aiken et al. 2001). Further analysis of the USA sample demonstrated that after adjusting for patient and hospital characteristics, each additional patient assigned to a nurse increased by $7 \%$ the risk of death within 30 days of admission and failure to rescue; risk to the nurse of burnout increased by $23 \%$ and job dissatisfaction by $15 \%$ (Aiken et al. 2002).

These concerns have also been found in New Zealand; where research indicates that $30-40 \%$ of nurses consistently intend to leave their job within 12 months (Cobden-Grainge \& Walker 2002: Finlayson \& Gower 2002). Persistently high job stress and dissatisfaction are not surprisingly reflected in $\mathrm{RN}$ recruitment and retention difficulties, reported by the Department of Labour(DoL) (2005). Results of a survey of employers who had recently advertised vacancies in 2004 , showed that there were few suitable applicants per vacancy 91.1 applications per vacancy), and only $63 \%$ of vacancies were filled within 8-10 weeks of advertising, meaning that existing staff and temporary nurses would be covering unfilled positions. Moreover, those advertised vacancies were for existing, not newly created, positions. suggesting that turnover is high. Lending support to nurses' complaints of being overworked, the DoL reported that employment of RNs grew by only $0.8 \%$ per annum in the decade 1991-2001, low compared to employment growth of doctors $(2.8 \%)$ and other health professionals $(2.1 \%)$.

Accompanying increased nurse workload and attendant outcomes for patients (increased mortality) and nurses (job dissatisfaction, burnout and intent to leave) has been a reported escalation in the use of and dependence on temporary cover mechanisms internationally. Temporary cover mechanisms are employed to manage chronic shortages of nurses, retention and recruitment difficulties, staff absences, a hiatus of 2-3 months between a leaving nurse's position being refilled, and variations in patient volume and acuity (Berney et al. 2005; Buchan \& Thomas, 1995; Cardona \& Bernreuter 1996; Manias et al. 2003). Also significant is that these developments have taken place in a context of increasing casualisation of the work force generally that has also affected nursing, reflecting what are seen as prohibitive costs of a $100 \%$ staffing model (Peerson et al. 2002); and is resulting in a trend toward "dejobbing", that is a fundamental shift from seeing one's self as occupying a position to contracting one's skills to meet work needs (Strasen \& Brock 1998). However research has shown that temporary cover mechanisms are no panacea. Seen as an easy way of 
reducing costs and increasing flexibility, criticisms of temporary cover mechanisms commonly employed include: reduced continuity of care; variable quality of temporary staff and concerns over continuing education; reduced quality of care and increased risk of liability; increased management time to arrange cover; reduced morale of permanent staff; and fatigue and burnout of permanent staff working overtime and assisting temporary nurses (Berney et al. 2005; Buchan \& Thomas, 1995; Manias et al. 2003; Peerson et al. 2002) and irregular and unknown exposure to continuing education (Meyer \& Siegel 1996). Advantages include the greater flexibility of managing staffing to manage fluctuations in demand and associated reduced costs, ability to manage chronic vacancies and short term absences, improved flexibility and other benefits for the agency nurses themselves (Buchan \& Thomas, 1995; Manias et al. 2003: Peerson et al. 2002).

Ways of providing temporary cover vary and reflect three main mechanisms. One mechanism concerns the use of overtime, a practice related to fatigue and the stress of overwork. A USA study using hospital operating cost data showed that between 1995-2000 overtime use increased by between $35-40 \%$, with nurses working an average weekly overtime of $4.5 \%$, up to $16.6 \%$, of total hours (Berney, Needleman \& Kover 2005). A second mechanism employed is the use of an in-house nursing resource variously referred to as a nurse bank or bureau. float team or resource team. This was found to be widespread in a survey of Scottish hospitals to improve flexibility and save on staff benefits (Buchan \& Thomas 1995). Savings on staff benefits are contestable in the light of a landmark UK employment tribunal decision awarding benefits on the basis of similar work for the organisation, irrespective of temporary or permanent status (Anonymous 2006).

A third commonly used mechanism is the use of nurses employed not by the hospital but by an external agency. A 2002 survey in Melbourne (Peerson et al. 2002; Manias et al 2003) uncovered high utilisation of agencies along with concerns over the difficulties in matching the qualifications and experience of the agency nurse to the needs of the contracting nursing service. Agency nurse use was higher where units were busy, where patient demand was fluctuating, in specialty areas with recruitment and retention problems, and where there were no permanent night staff (all staff rotated), but use was lower where staffing was stable. In spite of concerns over use of agency nurses health organisations were nevertheless dependent on them to manage vacancies, shortages, absences and variable patient volumes and acuity.

Few authors have addressed the issue of solutions. An exception is an evaluated trial of a policy decision to "over hire", that is to employ excess numbers of nurses, in that case new graduates, to reduce the number of vacancies resulting from the hiatus between a nurse's resignation and replacement (Cardona \& Bernreuter 1996). The study identified several benefits of overhiring: historical costs of temporary staff and overtime were much higher than wages for the overhires; likelihood of closing beds was reduced; liability risks were reduced; staff morale and loyalty was increased; and stability of the nursing workforce and strategic workforce management were enhanced. In the UK a recently published document sets out a series of best practices for managing temporary nursing staff, urging a strategic approach to use of temporary nurses in place of an ad hoc dependence to manage shortages and recruitment and retention difficulties (National Audit Office 2006). A strategic approach requires data: on usage patterns and trends, costs, reasons for use and relation to variables such as patient volume and acuity, seasons and days, turnover and vacancies. Also required are that setting of and filling nurse establishments are realistic, and there is clear policy governing the use of temporary staff and decision guidelines.

What, then, is the situation in New Zealand? Are nursing workforces managed strategically, as reflected in budgeted staffing levels, actual levels employed, reasons for and levels of use of temporary cover mechanisms? These are issues explored by analysing data collected for the Cost of Nursing Turnover study.

\section{Methods and Results}

The data used for this paper were collected as part of the New Zealand Cost of Nursing Turnover Study, conducted between 2004-2006 to determine the actual costs of nursing turnover, and the impacts on patient and nurse outcomes. The study used a protocol developed in Britain, was pilot tested by six countries including New Zealand (see Hayes et al. 2006; O’Brien-Pallas et al. 2006; North \& Hughes, 2006). In New Zealand after receiving ethical approval, 22 randomly selected general medical and surgical units participated in the study but three did not complete data collection and have been excluded from the analysis (a completion rate of $86.4 \%$ ). Information regarding nurse staffing models and practices (and other information) was collected from each unit at the start of the study. Data on temporary cover mechanisms, assumed in the protocol to be used primarily to cover vacancies, were collected systematically and longitudinally over a period of 12 months per ward. All unit managers participated in a series of follow-up telephone interviews when they commented on and offered explanations on some of the results for their unit.

In presenting the results first the context of nursing work is described in terms of occupancy rates and nurse staffing practices. Then data on RN budgeted and actual FTE are described. Turnover rates are reported and a correlation between FTE deficit and turnover demonstrated. Finally temporary staffing practices as a means to stop the gap between demand for nursing services and supply are reported. Unit managers' comments and explanations of the way nursing levels are set and temporary cover mechanisms used go some way to understanding staffing practices but do not satisfactorily explain the motivation for those practices. 


\section{Resourced Beds and Occupancy}

Table 1 shows the number of resourced beds (average 25.57 ) and occupancy rates (average $91.8 \%$ ). In many of the units there were additional unfunded beds, and these beds were also used as required to meet demand. Occupancy that exceeded $100 \%$ showed that a given bed was occupied by more than one patient in a 24 hour period. Average registered nursing care hours per patient per 24 hours was 4.99 hours. In some units the figure was precise when appropriate software was used; in others the figure was calculated based on average nurse and patient numbers.

Table 1: Resourced beds, occupancy rates and daily hours of care.

\begin{tabular}{|c|c|c|}
\hline $\begin{array}{c}\text { Resourced } \\
\text { beds }\end{array}$ & $\begin{array}{c}\text { Average } \\
\text { occupancy }\end{array}$ & $\begin{array}{c}\text { Ave RN hours } \\
\text { per patient per } \\
\mathbf{2 4} \text { hours }\end{array}$ \\
\hline Mean 25.57 & Mean $91.8 \%$ & Mean: 4.99 \\
\hline $\begin{array}{c}\text { Range } 19.08- \\
47.33\end{array}$ & $\begin{array}{c}\text { Range } 73 \%- \\
109.1 \%\end{array}$ & Range $3.07-9.8$ \\
\hline
\end{tabular}

\section{Staffing of Units and Nurse Staffing Practices}

Nursing budgets covered the following staff: unit manager (usually termed charge nurse); advanced clinical roles (clinical nurse specialists and educators); staff nurses covering four levels; unregulated roles (health care assistants, nurse assistants, enrolled nurses). Units were managed by charge nurses at I FTE per unit, with the support of a small number of advanced nurses-clinical nurse specialists and clinical nurse educators. See Table 2. Normally these advanced roles did not carry a patient load. To deliver direct patient care services, units were staffed by a mix of RNs working as staff nurses, with the assistance of unregulated roles (health care assistants, nurse assistants). In addition nursing staff were supported in delivering patient care with housekeeping support and allied health services, neither of which came from the nursing budget.

Table 2: Nursing staff of units in FTE per unit.

\begin{tabular}{|l|l|l|l|l|}
\hline $\begin{array}{l}\text { Unit } \\
\text { manager }\end{array}$ & $\begin{array}{l}\text { Clinical } \\
\text { nurse } \\
\text { specialist }\end{array}$ & $\begin{array}{l}\text { Clinical } \\
\text { nurse } \\
\text { educator }\end{array}$ & $\begin{array}{l}\text { Staff } \\
\text { nurses }\end{array}$ & Unregulated \\
\hline All units & $6 / 20$ units & $\begin{array}{l}12 / 20 \\
\text { units }\end{array}$ & All units & All units \\
\hline 1FTE & $\begin{array}{l}0.5-4 \\
\text { FTE }\end{array}$ & $\begin{array}{l}0.3-1 \\
\text { FTE }\end{array}$ & $\begin{array}{l}14.3- \\
45.63\end{array}$ & $\begin{array}{l}0.5-14 \\
\text { FTE }\end{array}$ \\
\hline
\end{tabular}

All except 1 ward rostered nurses on $3 x$ 8hour shifts; 1 rostered nurses on $2 \times 12$ hour shifts. Typically in day shifts there were $6 \mathrm{RNs}+1$ unregistered health care assistant or enrolled nurse, and on night shifts there were 2-3 RNs and 1 unregistered health care assistant

\section{Budgeted and Actual RN FTE}

When budgeting for the RN staff nurse FTEs the following factors need to be considered:

Figure 1: Budgeting for staff nurse numbers.

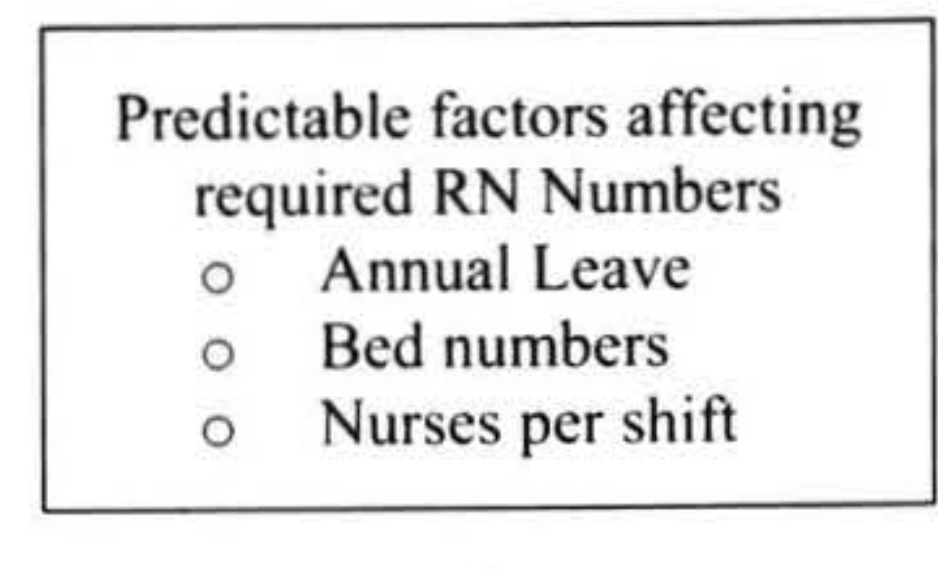

$+$

Unpredictable (low level)

factors affecting required $\mathrm{RN}$ number

- Sick leave

- Study leave

- Family leave

Table 3 shows data on RN (staff nurse) full time equivalents (FTE): mean budgeted FTE was 25.87 and mean actual RN FTE was 24.05 (median 25.48), with a range of 14.61-38.52. The difference between budgeted and actual FTE was on average -1.88 (median -1.74), with a range per ward per month of $-7.2-+2.26$.

Table 3: The average budgeted and actual FTE.

\begin{tabular}{|c|c|c|c|}
\hline & $\begin{array}{c}\text { Budgeted } \\
\text { FTE }\end{array}$ & $\begin{array}{c}\text { Actual } \\
\text { FTE }\end{array}$ & $\begin{array}{c}\text { Difference between } \\
\text { budgeted \& actual } \\
\text { FTE }\end{array}$ \\
\hline Mean & 25.87 & 24.05 & -1.88 \\
\hline Range & $\begin{array}{c}14.3- \\
45.63\end{array}$ & $\begin{array}{c}14.61- \\
38.52\end{array}$ & $-7.2-+2.26$ \\
\hline
\end{tabular}

The relationship between budgeted and actual RN FTE became a focus of discussion in follow-up interviews to discuss provisional results with unit managers and nurse leaders. Budgeted $\mathrm{RN}$ levels were set annually by management staff, and unit managers confirmed that the levels were expected to include annual leave and provide for sick and other unanticipated leave requirements. Few unit managers were involved in setting the budgeted RN level beyond being briefly consulted. Some did not know 
how the budget was arrived at and many felt that historical budgeted levels were no longer adequate to meet usual volumes and the generally high acuity levels that many unit managers stressed had increased along with a shorter length of stay.

In spite of their views that budgeted FTEs were inadequate, of particular note is the negative difference between budgeted and actual RN FTE of an average -1.88 FTE, up to -7.2 FTE. Unit managers were asked why actual RNs tended to be lower than budgeted: in many cases this was because RNs had left and there were delays in filling the vacancy, reflecting both the time it takes to fill a vacancy and difficulties in finding a replacement (see also DoL 2005). A few DHBs or wards preferred not to staff the ward to the budgeted level for various reasons. This practice gave them greater flexibility to staff according to variable demand; to help manage costs within the budget; to minimise the risk of RNs being redeployed on a shift by shift basis (a practice nurses disliked); and that RN budget savings allowed unit managers to purchase other services such as unregulated staff to support nurses. However there were also a few units where actual FTEs exceeded the budget. Those unit managers claimed that their primary concern was to provide a safe working environment both for patients and staff and this over-rode budget concerns. They also believed the budgeted FTE was inadequate and by consistently exceeding the budget delivered a message to managers responsible for setting the budget. Of particular relevance is that when actual $\mathrm{RN}$ levels were inadequate then temporary cover mechanisms were used, discussed below.

\section{Turnover Rates}

The turnover rate of the sample of units over one year was calculated per ward based on the following information:

1. FTE: Average budgeted FTE levels per ward were 25.87.

2. FTE Leavers: The total number of RNs who left the primary place of employment in the 12 month study period was 192.6 FTE.

The average national turnover rate after 12 months of data collection for all 19 wards was $39.16 \%$ with a range of $13.83 \%$ to $73.17 \%$. The turnover rate is artificially raised by the required 6 month rotations of new graduate RNs. If the total number of leavers is reduced by deducting new graduate second rotation figures (24), the average turnover rate falls to around $34.38 \%$ (see Table 4 ).

Table 4: Turnover rates (in percentages).

\begin{tabular}{|c|c|c|c|c|c|}
\hline Mean & Max. & Min. & $\begin{array}{c}\text { Total } \\
\text { FTE } \\
\text { leavers }\end{array}$ & $\begin{array}{c}\text { Total } \\
\text { FTE } \\
\text { joiners }\end{array}$ & $\begin{array}{c}\text { Mean } \\
\text { excl. } \\
\text { NG } \\
\text { 2nd }\end{array}$ \\
\hline 39.16 & 73.17 & 13.83 & 192.6 & 268 & 34.38 \\
\hline
\end{tabular}

A total of 192.6 FTE in 19 units left during the 12 months of data collection. Noting that the mean budgeted RN FTE per ward was 25.87 , the national average for one ward in one year was 10.14 leavers, with a range from 3.5 - 21.6, representing a turnover of nearly $40 \%$ of its RN staff annually. During the same period, a total of $268 \mathrm{RNs}$ joined the participating wards, giving an average of 13.4 new RNs per year per ward. Unit managers were asked whether the turnover in their ward in the 12 month data collection period was unusual. In many cases, the rate reflected normal patterns. Others remarked the turnover rate in the study period was unusually high and offered explanations: organisational change or restructuring had occurred around the time of the study; occupancy and acuity had been particularly high; and the environment stressful.

\section{Relationship between Turnover and FTE Deficits}

The relationship between turnover and FTE deficits was investigated using Spearman's rank order correlation. There was a medium, negative correlation between the two variables $[r=-.474, n=19, p<.040]$, with high levels of turnover associated with lower levels of staffing. That is, as actual FTE decreases below the budgeted FTE, turnover increases. Figure 2 shows a scatter gram demonstrating the relationship between higher turnover with lower actual FTE against budgeted FTE.

Figure 2: Scatter gram showing the negative relationship between turnover and the difference between budgeted and actual FTE.

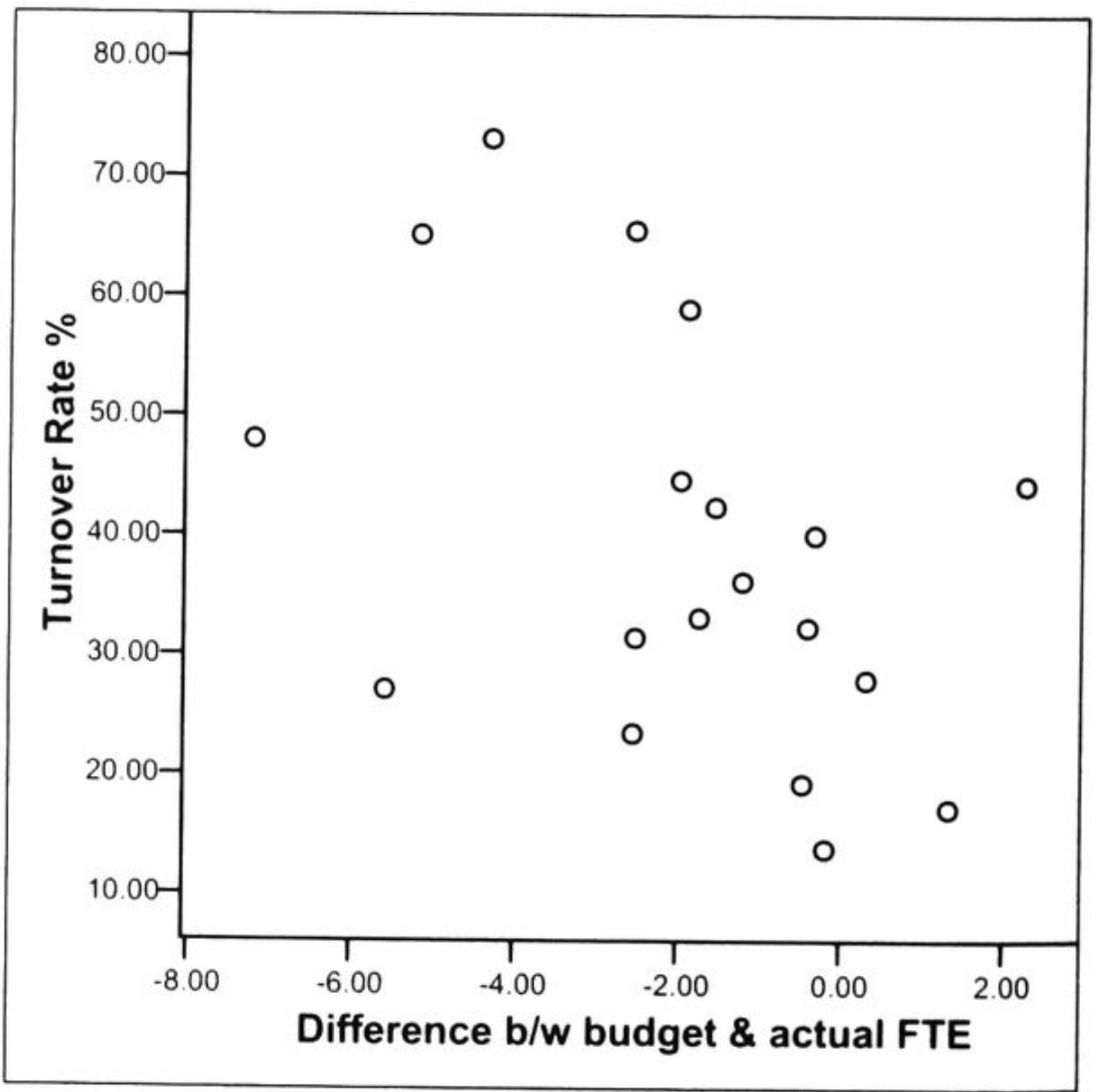

Use of Temporary Cover Mechanisms

When permanent rostered RN staff nurses were insufficient to meet demand for nursing services, temporary cover was used. All units used temporary cover, though the mechanisms and the purpose varied. Figure 3 shows the mechanisms employed. 
Figure 3: Temporary cover mechanisms used.

\author{
Mechanisms to cover shortages in RN numbers \\ - RN Overtime \\ - Redeployment from other wards \\ - Float/Resource nursing team \\ - Temporary RNs (in-house-bureau; external-agency) \\ - Unregulated Staff (nurse assistants) \\ - Maximising pressure on nurses (increase \\ productivity) \\ - Close beds \\ Reduced services
}

Overtime by permanent staff was commonly used, frequently involving permanent part-time staff nurses and also full-time nurses. Redeployment on a shift by shift basis from other units under less pressure was also widely used. The "float" or "resource" team refers to a pool of permanent employees who, like permanent staff nurses allocated to wards, are guaranteed work to a specified number of weekly hours; however the nurses work wherever the greater need is. Bureau (in-house) or agency (external) nurses also work wherever they are sent, but there is no guaranteed amount of work, nor are those nurses obliged to agree to work where and when requested. All hospitals had their internal bureau (other terms are bank, pool) and in metropolitan areas there were external agencies that hospitals could call on. RN substitution or extension by using unregulated staff from a bureau or pool (assistants, patient "watchers") was widely used, sometimes when an RN could not be found, other times when particular patients required the constant presence of an observer, but not necessarily by an RN. When no temporary $\mathrm{RN}$ could be found sometimes available nurses simply worked harder, and/or carried out the essential tasks (e.g. medications) while neglecting those that did not risk safety (e.g. not administering hot drinks). As a final resort when $\mathrm{RN}$ coverage was deemed too low to assure safety and quality of care, nurse managers had the authority to close beds temporarily or reduce services.

Unit managers differed in their use of and preference for different mechanisms. For example some unit managers avoided redeploying their staff as morale was negatively affected by being moved around at short notice. Others did not like using agency or bureau nurses and would rather use overtime. Some for professional reasons resisted nurse substitution. Asked to describe how they managed a RN shortage on a given shift, unit managers described a wide range of approaches based on the above mechanisms but differing on their priorities, preferences and organizational policies.

\section{Costs of Temporary Cover Mechanisms}

Different mechanisms carry different dollar costs. For example it is more expensive to use external agency RNs than the hospital's own employees; increased productivity -i.e. doing the same work with fewer staff- and redeployment do not show up on the balance sheet as a cost. In addition a common practice is for RNs working in wards that on a given shift are not busy to be moved temporarily to another ward that on a given shift is short of staff. This latter practice is seldom included in the calculation, but nevertheless carries a potential cost in its effect on staff health and job satisfaction. Closing beds and reducing services are not reflected in unit manager cost centre figures, although the costs related to loss of revenue, public confidence and expensive fixed assets lying idle is high. The dollar costs associated with temporary cover mechanisms were calculated to include:

- actual amount spent on temporary nurses;

- overtime:

- cost of time spent to arrange cover; and

- costs of time related to permanent staff introducing temporary staff to unit and in assisting or explaining things.

Temporary nursing staff - an average of $\$ 173,201$ was spent on temporary cover per ward per year (median $\$ 161,197)$, with a range of $\$ 31,743-\$ 374,152$. These costs were calculated based on actual amounts spent providing temporary staffing, including internal float or resource teams, internal bureau//pool, and external agency.

Overtime - an average of $\$ 11,028$ was spent on overtime per ward per year (median $\$ 2.904$ ), with a range of $\$ 0.00$ - $\$ 93.893$. Duration ranged from an hour or two to full shifts, with instances of double shifts being worked.

Administrative and management time to arrange temporary cover - an average of $\$ 11,813$ per ward per year (median \$12,227), with a range of \$3878 - \$22,461. The cost was calculated on amount of time spent on a daily basis by unit and other nurse managers, internal nursing bureau personnel and administrators multiplied by their hourly rates. Administrative practices varied: large DHBs had dedicated offices or personnel purely for the arrangement of temporary nursing staffing and smaller DHBs one to two persons dedicated to that task; others relied on the unit manager concerned to arrange that cover.

Cost of time for permanent staff to assist/ advise temporary staff - an average of $\$ 4,369$ per ward per year, with a range of $\$ 0.00-\$ 15,201$. The cost was calculated based on real-time recording of permanent RN staff time and level over the 12 month period. Costs associated with the provision of temporary cover are summarised on Table 5.

On exploring the high amounts spent on temporary staffing with participating unit managers, many raised concerns that temporary staffing mechanisms are not only to cover vacancies and therefore should not be a turnover cost. In many DHBs temporary cover was primarily used for other purposes including: sick leave, other leave such as bereavement leave and study leave, and higher than normal acuity and workload. Temporary cover was used for leave though budgeted RN levels in wards were deemed sufficient to cover workload and leave. However there was considerable variation reported; some claimed only a small level or none was used to cover vacancies 
with most used to cover sick leave and the like; others said that temporary cover mechanisms were only or mostly used for vacancies and shortages. Further complicating factors were different practices in staffing wards. Some deliberately employed fewer RNs than budgeted for, for such reasons as allowing for greater flexibility to cover fluctuating demand and to manage units within budget. Others endeavoured to employ RNs up to the budgeted level or to exceed the budgeted level when the budget was deemed inadequate for delivering safe care. Another reported practice was to use the nursing budget flexibly, for example to buy additional health care assistant time. While acknowledging that owing to differing practices and policies temporary cover is used to manage $\mathrm{RN}$ staffing, not only to cover vacancies and shortages, it also appeared that in some cases the budgeted level of RNs was insufficient to meet the demand. Based on data and unit manager explanations, use of temporary cover could be ascribed to one of three scenarios:

i. Scenario 1: budgeted $=$ actual RNs

Temporary cover is used for >acuity: >volume, $>$ staff sickness.

ii. Scenario 2: vacancies result in actual<budgeted.

Temporary cover is used for >acuity: >volume, $>$ sickness, and vacancies.

iii. Scenario 3: actual staffing is deliberately < budgeted:

Temporary cover is used to manage fluctuations as above and to create salary savings.

Table 5: Average costs per unit per year associated with temporary cover.

\begin{tabular}{|l|l|l|}
\hline & Mean & Range \\
\hline $\begin{array}{l}\text { Temporary } \\
\text { Nursing Staff }\end{array}$ & $\$ 173,201$ & $\$ 31,743-\$ 374,152$ \\
\hline $\begin{array}{l}\text { Overtime } \\
\text { Time arranging } \\
\text { temporary staff }\end{array}$ & $\$ 11,028$ & $\$ 0.00-\$ 93,893$ \\
\hline $\begin{array}{l}\text { Time assisting } \\
\text { temporary staff }\end{array}$ & $\$ 4,369$ & $\$ 0.00-\$ 15,201$ \\
\hline \begin{tabular}{l} 
TOTALS \\
\hline
\end{tabular} & $\$ 196,482.2$ & $\$ 35,621-\$ 505,707$ \\
\hline
\end{tabular}

In Scenario 1, temporary cover is not a cost of turnover; however questions remain about how realistic budgeted staff levels are. In Scenario 2, temporary mechanisms clearly are a direct cost of turnover, but salary savings related to unfilled vacancies need to be deducted from costs. Costs of temporary cover are also a turnover cost in Scenario 3 irrespective of the rationale for the practice.

\section{Discussion}

In the participating units although occupancy rates were high and according to unit managers acuity was also high, there was a mean negative $\mathrm{RN}$ staffing against budgeted levels. Furthermore, unit managers widely felt that budgeted RN FTE were insufficient to deliver safe levels of nursing services for the patient population. New Zealand and international research (Aiken et al, 2001,2002; Finlayson \& Gower 2002) indicating that nursing is an overworked occupation risking burnout and high stress among nurses is reflected in those findings. It is not surprising, therefore, that employers reported difficulty in filling RN vacancies (DoL, 2005)- difficulty that the DoL attributed to low numbers of applicants, high turnover, emigration of nursing skills and high occupational detachment with nurses choosing not to work in nursing.

Temporary cover mechanisms were widely used to cover the negative gap between budgeted and actual RN FTEs combined with high turnover rates, findings that were explored with unit managers. A primary concern of unit managers was related to professional issues: concerns were expressed about safe levels of staffing, quality patient care, and pastoral concern for their nurses. However unit managers were in the invidious position where multiple, often competing, demands intercepted: they were required to manage the unit within budget, to support organisational strategy, to manage quality of care, were responsible for health and safety of staff and for professional development of nurses. However, generally unit managers did not strategically or operationally participate in the setting of RN FTEs required to meet demand, nor were they able to fill vacancies quickly and efficiently, leading to their reliance on temporary cover mechanisms. Mechanisms of temporary cover and costs reflect those reported in literature reviewed (Berney et al. 2005; Buchan \& Thomas 1995; Manias et al. 2001; Peerson et al. 2002).

These authors also identified drawbacks of temporary cover mechanisms. Working at the point of delivery of nursing services, unit managers were well aware of the drawbacks, but they were seldom in a position to reduce their reliance on temporary cover. Those drawbacks included the demand on manager time and resources, the demand on permanent staff working overtime and assisting external nurses, and the limitations of temporary nurses regarding skills, familiarity with the workplace and productivity. Given these concerns, annual average expenditure at these levels on temporary cover mechanisms is worthy of serious and critical attention with a view to determining how best to use the nursing budget.

The results demonstrate that at an organisational level setting the nursing FTE budget, staffing to the budgeted level and use of temporary cover are largely driven by considerations of costs, not strategic and professional considerations. A more important question, however, regards the costs to which a dollar figure cannot be easily ascribed. These costs reflect the high levels of burnout and job dissatisfaction found in studies cited above, low morale, the difficulties reported by employers in recruiting nurses along with high occupational detachment and emigration by nurses (DoL 2005) and high turnover found in the present study. Instability of nursing workforces and increased patient load, both found in the present study, have been demonstrated to be 
directly related to higher patient mortality (Aiken et al. 2002).

In the light of international experiences the future supply of a competent nursing workforce cannot be assumed. In Australia, the UK and the USA, where reliance on temporary cover mechanisms - particularly nurses external to the organisation - is much longer and more widespread than in New Zealand, temporary cover has emerged as a focus of research into the use, impacts on both temporary and permanent nurses, and implications for patient care quality. There are specific recommendations arising from such studies (National Audit Office 2006; Manias et al. 2001; Peerson et al. 2002; Cardona \& Bernreuter 1996; Buchan \& Thompson 1995; Berney et al. 2005) that could usefully inform policy development in New Zealand hospitals. In particular a critical examination of the present nurse staffing levels, the use of temporary cover mechanisms and the development of guidelines governing their use are warranted in the light of findings of the present study.

\section{Conclusions}

This study provides evidence to guide policy and practice decision making regarding the nursing workforce. In a context of high turnover, reducing supply, an ageing workforce approaching retirement and increased demand for nursing services, an obvious human resource strategy is to focus on retention. However working environments that maximises productivity of nurses through flexible use of the nursing resource and budget, extends nurse capacity with the use of unregulated workers, and relies on temporary cover mechanisms is antithetical to retention. A priority is to establish human resource management systems to determine, monitor, and review appropriate nurse establishments and to manage the use of temporary cover. The impact of current and future patterns of use of temporary cover on key indicators and outcomes needs to be monitored to guard against patient outcomes and the health and safety of nurses being secondary considerations to those of cost.

\section{Future Research}

Acknowledging that use of temporary cover was not the primary focus of the present study, the findings highlight the need for further research. It is important to investigate unit managers' claims that budgeted RN levels are inadequate to do the job. A more focused investigation on the costs and consequences for patients, nurses and health systems, at their broadest, of staffing practices and strategy, related to productivity, flexibility, temporary replacement and nurse substitution, is indicated. And research into nurse retention is required, particularly in the context of an ageing population that is increasing demand for nursing services.

\section{References}

Aiken, L., Clarke, S., Sloane, D., Sochalski, J., Busse, R., Clarke, H., Giovanetti, P., Hunt, J., Rafferty, A.M. and Shamian, J. (2001). Nurses' reports on hospital care in five countries. Health Affairs. 20(3), 43-53.

Aiken, L., Clarke, S., Sloane, D., Sochalski, J. and Silber, J. (2002). Hospital nurse staffing and patient mortality, nurse burnout, and job satisfaction. Journal of the American Medical Association, 288(16), 1987-1993.

Anonymous. (2006). Nursing Standard, 20(46), 11.

Berney, B., Needleman, J. and Kovner, C. (2005). Factors influencing the use of registered nurse overtime in hospitals, 1995-2000. Journal of Nursing Scholarship. 37(2), 165-172.

Buchan, J. and Thomas, S. (1995). Managing temporary nursing staff: Nurse banks in Scotland. Health Manpower Management, 21(1), 23-27.

Cardona, S. and Bernreuter, M. (1996). Graduate nurse overhires: A cost analysis. Journal of Nursing Administration, 26(3), 10-15.

Cobden-Grainge, F. and Walker, J. (2002). New Zealand Nurses' Career Plans. Christchurch: Nursing Education and Research Foundation.

Department of Labour (2005). Registered nurse: Occupational skill shortage assessment. Wellington: Department of Labour.

Finlayson, M. and Gower, S. (2002). Hospital restructuring: Identifying the impact on patients and nurses. Praxis, 18(1), 27-35.

Hayes, L.J, O'Brien-Pallas, L., Duffield, C., Shamian, S., Buchan, J., Hughes, F., Spence Laschinger, H.K., North, N. and Stone, P.W. (2006). Nurse turnover: A literature review. International Journal of Nursing Studies, 43(2), 237-26.

Manias, E., Aitken, R., Peerson, A., Parker, J. and Wong, K. (2003). Agency nursing work in acute care settings: Perceptions of hospital nursing managers and agency nurse providers. Journal of Clinical Nursing, 12(4), 457-466.

Meyer, S. and Siegel, M. (1996). How much is enough? Agency nurse orientation. Journal of Nursing Staff Development. 12(1), 41-42.

National Audit Office (2006). Good Practice in Managing the Use of Temporary Nursing Staff. UK: Department of Health. 
North, N. and Hughes, F. (2006). Methodological challenges to researching nursing turnover in New Zealand: A progress report of a national study. Asia Pacific Journal of Health Management 1(1), 45-51.

O’Brien-Pallas, L., Griffin, P., Shamian, J., Buchan, J., Duffield, C., Hughes, F., Laschinger, H., North, N., Stone, P. and Hayes, L. The impact of nursing turnover on patient, nurse and system outcomes: A pilot study and focus for a multicentre study. Policy, Politics and Nursing Practice, 7, 169-179.

Peerson, A., Aitken, R., Manias, E., Parker, J. and Wong, K. (2002). Agency nursing in Melbourne, Australia: A telephone survey of hospital and agency managers. Journal of Advanced Nursing 40(5), 504-512.

Strasen, L. and Brock, R. (1998). Preparing for the 'dejobbed' world of work. Journal of Nursing Administration. 28(7/8), 3-5.

\author{
Authors \\ Nicola North \\ Associate Professor \\ School of Nursing \\ The University of Auckland \\ Private Bag 92019 \\ Auckland Mail Centre \\ Auckland \\ N.North ( $a$ auckland.ac.nz \\ Frances Hughes \\ Adjunct Professor \\ Faculty of Nursing. Midwifery and Health \\ University of Technology Sydney \\ P.O. Box 123 \\ Broadway NSW 2007 \\ Australia \\ frances.hughes@clear.net.nz
}

Erling Rasmussen

Associate Professor

Department of Management and Employment Relations

The University of Auckland

Private Bag 92019

Auckland Mail Centre

Auckland

E.Rasmussen@auckland.ac.nz

Mary Finlayson

Associate Professor

School of Nursing

The University of Auckland

Private Bag 92019

Auckland Mail Centre

Auckland

M.Finlayson@auckland.ac.nz

Toni Ashton

Associate Professor

School of Population Health

The University of Auckland

Private Bag 92019

Auckland Mail Centre

Auckland

T.Ashton@auckland.ac.nz

Taima Campbell

Executive Director

Nursing and Midwifery

Auckland District Health Board

Private Bag 92-024

Auckland

TaimaC@adhb.govt.nz

Sharon Tomkins

Research Assistant

School of Nursing

The University of Auckland

Private Bag 92019

Auckland Mail Centre

Auckland

S.Tomkins@auckland.ac.nz 